\title{
Ethical Considerations in Dementia Diagnosis and Care
}

\section{AAN Position Statement}

\begin{abstract}
Winston Chiong, MD, PhD, Amy Y. Tsou, MD, Zachary Simmons, MD, Richard J. Bonnie, LLB, and James A. Russell, DO, on behalf of the Ethics, Law, and Humanities Committee (a joint committee of the American Academy of Neurology, American Neurological Association, and Child Neurology Society)*
\end{abstract}

Neurology ${ }^{\circledR}$ 2021;97:80-89. doi:10.1212/WNL.0000000000012079

\section{Abstract}

Alzheimer disease and other dementias present unique practical challenges for patients, their families, clinicians, and health systems. These challenges reflect not only the growing public health effect of dementia in an aging global population, but also more specific ethical complexities including early loss of patients' capacity to make decisions regarding their own care, the stigma often associated with a dementia diagnosis, the difficulty of balancing concern for patients' welfare with respect for patients' remaining independence, and the effect on the physical, emotional, and financial well-being of family caregivers. Caring for patients with dementia requires respecting patient autonomy while acknowledging progressively diminishing decisional capacity and continuing to provide care in accordance with other core ethical principles (beneficence, justice, and nonmaleficence). Whereas these ethical principles remain unchanged, neurologists must reconsider how to apply them given changes across multiple domains including our understanding of disease, clinical and legal tools for addressing manifestations of illness, our expanding awareness of the crucial role of family caregivers in providing care and maintaining patient quality of life, and societal conceptions of dementia and individuals' personal expectations for aging. This revision to the American Academy of Neurology's 1996 position statement summarizes ethical considerations that often arise in caring for patients with dementia; although it addresses how such considerations influence patient management, it is not a clinical practice guideline.

\author{
Correspondence \\ Dr. Chiong \\ winston.chiong@ucsf.edu
}

\section{RELATED ARTICLE}

\section{Editorial}

AAN's First 21st-Century

Position Statement on

Ethical Consideration in

Dementia Diagnosis and

Care

Page 57

From the Department of Neurology (W.C.), University of California San Francisco; Evidence-Based Practice Center (A.Y.T.), ECRI, Plymouth Meeting, PA; Division of Neurology (A.Y.T.), Michael J. Crescenz Veterans Affairs Medical Center, Philadelphia; Department of Neurology (Z.S.), The Pennsylvania State University, Hershey; School of Law (R.J.B.), University of Virginia, Charlottesville; and Department of Neurology (J.A.R.), Lahey Medical Center, Burlington, MA.

Go to Neurology.org/N for full disclosures. Funding information and disclosures deemed relevant by the authors, if any, are provided at the end of the article. 


\section{Glossary}

AD = Alzheimer disease; DSM-5 = Diagnostic and Statistical Manual of Mental Disorders, 5th edition; POLST = Physician Orders for Life-Sustaining Treatment.

Dementia and dementia care have undergone important changes since the Ethics, Law, and Humanities Committee, a joint committee of the American Academy of Neurology, American Neurological Association, and Child Neurology Society, addressed ethical issues in dementia a quarter-century ago. ${ }^{1}$ Scientific understanding has advanced considerably, with greater recognition of non-Alzheimer dementias and mixed dementia; new evidence for a long prodromal or asymptomatic phase of neurodegenerative causes of dementia; related advances in genetics, neuroimaging, and biomarker testing; and several large-scale clinical trials of agents intended as disease-modifying therapies for Alzheimer disease $(\mathrm{AD})$. Clinical practice has changed with approval of broader but still unsatisfactory treatment options such as cholinesterase inhibitors and memantine, greater awareness of pharmacologic risks of sedatives and neuroleptics, diminished use of tube feeding and physical restraints in care settings, and expanded use of hospice and palliative care. In the legal and ethical domain, conceptions of decisional capacity and models of capacity assessment have been refined; use of advance care planning has expanded; greater attention is now paid to the role and needs of family caregivers; and abuse (physical, financial, and otherwise) of vulnerable older adults has been increasingly recognized. Perhaps most significant are broader societal changes: whereas widespread stigma ${ }^{2}$ remains a barrier to patient care and advocacy, patients and families (alongside clinicians and other stakeholders) have engaged in broad action to promote awareness, advocate for research, and build more dementia-friendly communities.

This changing scientific, clinical, legal/ethical, and social landscape presents challenges for neurologists and other clinicians, in seeking to provide care consistent with applicable law and standing ethical and clinical consensus. Although not every ethical problem can be anticipated, this position statement presents an overview of ethical dilemmas that commonly arise in caring for patients with dementia; references are also provided to more extensive analysis of selected topics. This position statement first considers the diagnosis of dementia; genetic and biomarker testing are considered here as they are increasingly used to make or confirm a diagnosis of dementia or identify individuals at risk. Next, problems in decision-making are addressed, including the central topics of capacity assessment and advance care planning, which should be anticipated and addressed early in the course of illness. The following section concerns symptom and behavioral management, which pose problems that vary with dementia stage. Finally, the relationship between dementia care and society is considered, particularly in the context of American society and health care. This document focuses on ethical issues that arise in clinical care; ethical issues in research, including with patients who have cognitive impairments, are addressed elsewhere. ${ }^{3}$

\section{Complexities in Communicating the Diagnosis}

In communicating the diagnosis, clinicians may find that patients and family members often have different understandings of terms such as "dementia" and "Alzheimer disease." Because the term dementia has lay connotations of insanity and mental deficiency, some experts have argued for abolishing the term as hurtful and derogatory. ${ }^{4}$ The most recent edition of the DSM-5 generally omits references to dementia in favor of a more general term, "major neurocognitive disorder." Although we retain the term dementia, it should be used with sensitivity and awareness of potential negative connotations. Furthermore, when communicating with patients and families, neurologists should acknowledge widespread misconceptions and clarify what they mean by the term dementia, acknowledging also that its use by other clinicians may be different.

\section{Not All Dementia Is the Same}

While $\mathrm{AD}$ is the most common form of dementia, patients and families may benefit from knowing that $\mathrm{AD}$ is only one among many different causes of dementia, that dementia is not exclusively a disease of advanced age, and that symptoms can differ significantly across individual patients. For instance, although dementia may be commonly understood to primarily involve memory impairment, mood and behavioral changes often have more of an effect on patients and families than declines in memory or cognitive function. Thus, expectations based on observing other patients or on cognitive test scores may not predict the most consequential features of the patient's clinical course.

Because dementia is often considered to be exclusively a disease of aging, middle-aged and younger patients with conditions such as early-onset $\mathrm{AD}$, frontotemporal dementia, and Huntington disease face unique problems, as do their families. As earlier onset forms of dementia often present with socioemotional and behavioral disturbances before typical cognitive complaints, diagnosis of sporadic disease is often delayed and patients' behaviors may be misinterpreted as manifestations of a psychiatric rather than a neurologic disorder. Such patients are often midcareer rather than retired and may have children at home, increasing safety concerns and burdens for other family members. Community resources 
such as adult day programs, nursing facilities, and caregiver support groups are also often designed principally for the needs of older patients. Clinicians should anticipate devoting greater time to caregiver education and to identifying resources for such patients; referral to specialty centers is often also useful (see also Genetic and Biomarker Testing).

\section{Truth-Telling and Disclosure}

Prior to communicating a diagnosis, it is important to ascertain how much information patients wish to receive and how they prefer to receive information. Some patients defer to family members or other trusted people who can receive information on their behalf (see also Socioeconomic, Ethnic, and Cultural Factors). In the past, clinicians have sometimes invoked therapeutic privilege to justify withholding information (such as a diagnosis of dementia) deemed too devastating or otherwise harmful to the patient, and clinicians now may receive requests from family members to withhold a diagnosis from the patient due to related concerns. However, unless patients who have capacity specifically make a request that such information be given to others rather than directly to them, such nondisclosure violates patient autonomy, undermines trust, reinforces stigma, and may deprive patients and families of important opportunities to plan for future needs. ${ }^{6}$ For patients without decisional capacity, the diagnosis should be disclosed to a legally recognized surrogate decision-maker (see Decision-Making in Dementia) and in most cases also to the patient; in some cases disclosure to the patient may require planning with the surrogate.

It is important to consider the setting and manner of disclosure to minimize the risk of emotional harm to the patient; for instance, involving another clinician with a longstanding relationship with the patient, or facilitating the presence of family members or other loved ones to provide support and assist in recalling details that patients with memory disorders are prone to forget. Involvement of trusted family and friends can also prevent misunderstanding of patients' symptoms and behavior, mitigate social isolation, and facilitate advance care planning. Frameworks established for communicating serious diagnostic or prognostic information, such as the SPIKES protocol (setting, perception, invitation, knowledge, emotion, and strategy and summary), ${ }^{7}$ identify important aspects of such encounters. In most cases, family members' fears about potential emotional harm can be assuaged by thoughtful and compassionate disclosure using these strategies.

\section{Genetic and Biomarker Testing}

Degenerative dementias may infrequently result from monogenic, mendelian mutations, but more commonly arise from an interplay among genetic, environmental, and lifestyle factors. A rapidly evolving menu of tests is now available that in symptomatic individuals may be used to confirm the existence and cause of dementia, or in asymptomatic/presymptomatic persons may suggest future risk for cognitive decline. Ethical considerations in testing hinge on whether the testing will be performed in a clinical or research context, whether the patient is symptomatic or at increased risk of developing dementia, potential implications for other family members, and whether the testing will be diagnostic or solely imply heightened risk.

Genetic testing may be diagnostic in symptomatic individuals with dominantly inherited dementias (such as Huntington disease) and with familial forms of $\mathrm{AD}$, frontotemporal dementia, and prion disease. It can also predict illness in presymptomatic carriers of pathogenic genetic variants. Other gene polymorphisms such as $A P O E$ are not diagnostic but modify individuals' risk for developing dementia. CSF and PET biomarkers of amyloid and tau aggregation are now also being used to diagnose symptomatic patients with atypical presentations of dementia. In research settings, such biomarkers may provide evidence of pathologic involvement in asymptomatic individuals, ${ }^{8}$ raising ethical questions about potential uses in predicting clinical $\mathrm{AD}$ among healthy people.

Clinical research regarding genetic and biomarker testing is rapidly transforming our understanding of $\mathrm{AD}$ and other dementias. However, translation of these tools into clinical practice is ethically fraught. Early and accurate detection offers potential benefits including diagnostic closure, family planning, and opportunities for advance care planning. Potential harms, particularly when testing asymptomatic individuals, may include adverse psychological responses, confusion provoked by genetic variants of unknown significance and variable penetrance, and vulnerability to discrimination.,10 Accordingly, informed consent, which may be challenging in this context (see Decision-Making in Dementia), is requisite for genetic or biomarker testing in degenerative dementias.

Genetic testing should be offered to symptomatic patients who have phenotypes associated with autosomal dominant inheritance (e.g., early-onset $\mathrm{AD}$, frontotemporal dementia, Huntington disease, and prion diseases) and supportive family histories. Similarly, biomarker testing and disclosure may be clinically useful for some symptomatic patients with atypical presentations or other reasons for diagnostic uncertainty (regardless of family history). In asymptomatic, atrisk adult relatives of patients with autosomal dominant dementias such as Huntington disease, predictive testing may be offered with requisite counseling about the absence of disease-modifying treatments and the potential life consequences of both positive and negative test results. ${ }^{9,10}$ Currently, for asymptomatic individuals, genetic susceptibility testing and biomarker testing are recommended solely in a research setting. ${ }^{11-13}$ This is largely due to potential harms (as previously noted) and the absence of interventions capable of favorably altering the natural history of the disease.

Any patient undergoing genetic testing should receive genetic counseling before and after receiving results; in addition, patients should be informed of relevant legal protections offered through the Genetic Information Nondiscrimination Act (GINA) and other legislation. ${ }^{14}$ (Of note, individuals with positive biomarkers are not protected by current regulations 
from employment or insurance discrimination. ${ }^{15}$ ) Formally trained genetic counselors are unavailable in many practice settings. In such cases, the ordering neurologist should either develop competency in personally providing such counseling or arrange access to genetic counseling through telemedicine if available. ${ }^{16}$ Genetic testing should be performed at an accredited laboratory after appropriate pretest counseling and informed consent. ${ }^{17}$ Neurologists must be prepared to discuss findings with patients who have already received results without pretest counseling (e.g., direct-to-consumer genetic testing) and to assure that patients receive posttest genetic counseling if needed.

\section{Decision-Making in Dementia}

\section{Appropriate Involvement of the Patient at Different Stages}

Given the progressive cognitive decline typically observed in dementia, most patients will eventually become unable to make medical, legal, and financial decisions independently. For patients in early stages who retain decision-making capacity, timely anticipatory planning is crucial to preserve autonomy over future decisions and reduce future strains on caregivers. Patients with mild cognitive impairment and in mild stages of dementia should be encouraged to discuss their overall goals with their families and clinicians and to execute advance health care directives and other documents to guide decision-making in the event of incapacity. In moderate stages of dementia, many patients who lack formal decisional capacity may still be able to participate meaningfully in decision-making; for instance, by conferring with surrogate decision-makers about values that should guide care decisions.

\section{Capacity Assessment}

Many ethical questions in dementia care stem from questions regarding whether (or to what extent) patients retain decisional capacity. Thus, all clinicians caring for patients with dementia should be conversant with principles for assessing capacity. Rarely, psychiatric consultation (e.g., for patients with prior histories of mental illness) or formal forensic assessments (e.g., in borderline cases with significant intrafamilial disputes over the disposition of a patient's assets) may be warranted. Notably, determinations of capacity are always made relative to a particular decision: thus, patients may be judged capable of making some clinical decisions, and incapable of making others. Capacity is not determined simply by diagnosis or scores on cognitive testing. Instead, capacity assessment relies upon a clinician's judgment (often informed by diagnoses, cognitive scores, and other clinical data) regarding the patient's functional ability to provide valid informed consent to medical care and to make valid legal and financial decisions.

One widely accepted model posits 4 component abilities necessary for capacity to make a given decision: understanding, appreciation, reasoning, and choice. ${ }^{18}$ Understanding here represents a grasp of basic facts such as the nature of one's condition, the proposed intervention, the alternatives, and their risks and benefits and may be assessed by asking patients to rephrase provided information in their own words. Appreciation represents recognition of how this information applies to one's own case (related to insight) and may be assessed by asking patients to give a plausible explanation for why a proposed course of action will or will not benefit them. Reasoning includes the ability to compare options and consistently infer their consequences and may be assessed by asking patients how an available option would affect their daily lives. Choice is a matter of expressing a decision, which should be reasonably stable in the absence of new information. The application of such specific legal standards may improve the interrater reliability of capacity assessments. ${ }^{19}$

\section{Advance Care Planning}

It is crucial to encourage advance care planning while patients still have capacity. This facilitates completion of appropriate documents (see the table) conferring legal authority to decision-making surrogates, which preserves a measure of patient autonomy and often spares caregivers a lengthy court process. It is particularly important that the patient choose a surrogate he or she believes is intellectually and emotionally capable of making decisions aligned with the patient's own values (even if these values conflict with the surrogate's values; see Making Decisions for Patients Without Capacity) and communicating with clinicians on their behalf.

Whereas completing an advance health care directive is an important component of advance care planning, this document should not be viewed as the goal or endpoint of planning. When making advance directives, patients are often unable to anticipate the specific circumstances in which they will require care, and appointed surrogates may not know what patients would want in health crises. ${ }^{20}$ Consequently, advance care planning should be viewed as a process of engaging with patients and their chosen surrogates to explore patients' values and prepare surrogates for their role in medical decision-making. ${ }^{21}$ Patients should know that failure to plan often results in aggressive care by default, which may not conform to their wishes, and may also require families to later undergo burdensome legal proceedings for appropriate authority. In addition, many important decisions involve complex legal and financial issues beyond most clinicians' expertise. Many patients could benefit from early conversations with an attorney specializing in elder or disability law to discuss these elements of their care plans, as patients may lose the capacity to address them relatively early in course of illness.

\section{Making Decisions for Patients Without Capacity}

Decision-makers for patients without capacity for a given decision should give first priority to known preferences expressed by the patient when he or she had capacity (i.e., in an advance directive or clear oral statement). If no explicit statement of the patient's wishes exists, surrogates should apply "substituted judgment," attempting to determine what the patient would have wanted, based on knowledge of the 
Table Advance Planning Documents for Medical, Legal, and Financial Surrogate Decision-Making (Terminology, Legal Requirements, and Specific Powers Vary Among States)

\begin{tabular}{|c|c|c|}
\hline & Medical decisions & Legal/financial decisions \\
\hline $\begin{array}{l}\text { Authority from the patient (created } \\
\text { when patient had capacity) }\end{array}$ & $\begin{array}{l}\text { Advance health care directive: } 2 \text { broad types, although } \\
\text { many directives include both: } \\
\text { Durable power of attorney for health care: names a } \\
\text { health care agent (in some states called a proxy or } \\
\text { representative) to make decisions if the patient no } \\
\text { longer can; usually the most important document for } \\
\text { patients to have } \\
\text { Instruction directive (sometimes called a "living will"): } \\
\text { traditionally used to list treatments (like } \\
\text { cardiopulmonary resuscitation or mechanical } \\
\text { ventilation) that the patient would or would not want in } \\
\text { end-of-life situations; in dementia, more usefully } \\
\text { applied to document the patient's overall values and to } \\
\text { consider behavioral management and placement } \\
\text { decisions that can arise in middle stages of illness } \\
\text { (see Symptom and Behavioral Management) }\end{array}$ & $\begin{array}{l}\text { Many patients would benefit from legal advice to } \\
\text { discuss various forms of financial surrogacy, including: } \\
\text { Durable power of attorney for finances. Names an } \\
\text { agent to manage the patient's money and property. } \\
\text { Living trust. A legal tool naming a trustee to manage } \\
\text { decisions about money or property during the patient's } \\
\text { lifetime as well as in death. } \\
\text { Social Security Representative Payee or Veterans' } \\
\text { Administration Fiduciary. Individuals named to } \\
\text { manage Social Security or veterans' benefits on behalf } \\
\text { of patient. }\end{array}$ \\
\hline
\end{tabular}

Authority from the state (may require a court process, often but not always avoidable with advance planning)
Default surrogates-if an incapacitated patient has not
designated a health care agent, many but not all states have statutes automatically appointing a surrogate from an ordered list of relatives; state laws vary considerably, and may limit the scope of a default surrogate's legal authority (e.g., over end-of-life decisions or clinical research) ${ }^{60}$

Guardianship (in some states called conservatorship or conservatorship of the person)-if a patient lacks capacity and does not have an appropriate surrogate, a judge will appoint someone to make decisions for them; family members or friends may petition to be named the patient's guardian; other options include professional (paid) and public guardians
No default financial surrogates-generally, families do not have authority to make financial or other legal decisions for the patient; a spouse has very limited authority unless also named as an agent, trustee, or conservator

Conservatorship (in some states called guardianship/conservatorship of the estate)-if a patient does not have an agent or trustee and lacks capacity, a judge will appoint someone to make decisions for him or her; family members or friends may petition to be named the patient's conservator; other options include professional (paid) and public conservators patient's general values and beliefs when capacity was present. Finally, if there is insufficient information for substituted judgment, physicians and surrogates should attempt to determine what is in the best interest of patients. Such judgments can be difficult and subjective; in particular, healthy people usually underrate the quality of life of patients with chronic disabilities as judged by those patients. ${ }^{22}$ Even when patients lack capacity, it is often still helpful to invite them to participate in broader conversations about the values guiding decisions about their care.

Surrogate decision-makers should be aware that their role is to try to decide as the patient would under the circumstances; in many cases this approach can mitigate subsequent guilt or regret, as the surrogate need not bear full responsibility for decisions that reflect the patient's wishes rather than their own personal wishes. As the illness progresses, clinicians and surrogates should consider medical decisions for patients in the context of the overall goals of care. These goals should be informed by the patient's stated wishes and values, as well as by considering how patients' aims would change in response to clinical developments and assessing what available interventions are likely to achieve. For many patients, it will be appropriate to write do-notresuscitate or do-not-hospitalize orders if either resuscitation or hospitalization is deemed inconsistent with patient goals. Many states have passed laws for Physician Orders for Life-Sustaining Treatment (POLST; acronyms and terminology vary across states), which, unlike traditional resuscitation and intervention orders, apply across institutions and also to emergency responders in home and public settings. Although useful for many patients, POLST documents are powerful tools that require cautious application; in particular, they do not substitute for advance directives and are typically appropriate only in advanced stages of illness. ${ }^{23}$ If implemented, POLST forms should be reviewed regularly to ensure that they are appropriate to the patient's current clinical status and the patient's current wishes (or an appropriate surrogate's understanding of their wishes).

\section{Symptom and Behavioral Management}

\section{Early Stages: Balancing Independence and Risk}

Many ethical conflicts encountered in mild cognitive impairment and mild dementia concern the extent of patient involvement in instrumental activities of daily living, such as driving, cooking, political participation, and managing finances, especially as patients may lack sufficient insight to monitor their performance. These activities are central to many patients' identities, but may expose them to personal risks, and in some cases could also endanger patients' families or the public. Conversely, restricting patient activity can also expose them to risks. For example, while patient financial mismanagement can result in catastrophic monetary losses, delegation of broad financial powers to poorly prepared or unscrupulous family members can expose patients to financial exploitation. ${ }^{24}$ Another risk of restricting activities is exacerbating social isolation, which can contribute to depression and 
worsening cognitive decline. ${ }^{25}$ Clinicians and family members should remain cognizant that no approach can eliminate risks and remain alert to ways of monitoring patients' activities to mitigate risks while preserving patients' independence and dignity where possible.

Driving in patients with dementia poses several ethical challenges. While a diagnosis of dementia does not automatically mean a patient cannot drive, patients should anticipate becoming unable to drive safely as their condition progresses, at which point many will lack sufficient insight to make this determination on their own. The American Academy of Neurology has issued a practice parameter that may help to identify patients at increased risk of unsafe driving. ${ }^{26}$ Even when guided by the best evidence and intentions, conversations with patients about restrictions on driving are often contentious; involvement of family members and friends can be helpful to facilitate such conversations.

\section{Moderate Stages: Agitation and Disruptive Behaviors}

About half of patients with dementia exhibit agitated behaviors such as wandering, accusations, nighttime awakening, and violence. ${ }^{27}$ These behaviors contribute to caregiver burnout, interfere with personal care, and can endanger patients as well as others in the care setting; such problems are often key factors in the breakdown of home care leading to institutionalization. ${ }^{28}$ Decisions about nursing home or memory care placement can be especially challenging, often intersecting with cultural expectations about filial obligations to aging parents, intrafamilial conflicts regarding the disposition of assets, caregivers' own employment and living circumstances, and what are sometimes inflexible beliefs and commitments ("I promised Dad I'd never put him in a home"). Clinicians can often help caregivers maintain patients at home with advice on person-centered communication, behavioral management, and environmental modification, ${ }^{29}$ as well as appropriate referral to resources such as advocacy organizations, support groups, caregiver respite, legal aid, adult day programs, and in-home services (see also The Caregiver Role). However, for many families, clinicians should encourage candid reassessments of whether in-home care remains feasible when disrupted sleep and physical or emotional strain interfere with caregivers' self-care, work, and other obligations.

In domestic and institutional care settings, disruptive and combative behaviors can harm the patient and threaten the safety of other residents or staff. The use of mechanical restraints (including bed rails) is now broadly rejected in both practice and policy ${ }^{30,31}$ as they can paradoxically increase physical risks to patients via increased agitation, improper application, forced immobility, and masking reversible causes of delirium. In rare cases with no realistic alternative for preserving the safety of the patient and others, the least restrictive possible restraint should be applied following an informed consent discussion (usually, with the patient's representative) including disclosure of risks and alternatives; their necessity and utility should then be continually reassessed. Pharmacologic restraints, as with benzodiazepines or neuroleptics, also require careful consideration given associated risks of exacerbated delirium, extrapyramidal symptoms, and excess mortality ${ }^{32}$; the Food and Drug Administration has issued a black box warning for atypical antipsychotics. In many cases these medications worsen patients' behavioral symptoms and increase the risk of complications due to polypharmacy, so nonpharmacologic strategies ${ }^{29}$ should be exhaustively explored first. If nonpharmacologic approaches are unsuccessful, clinicians should weigh the risks of pharmacologic treatment against other ethically important considerations such as the safety of patients and those living with them, patient quality of life (e.g., if compromised by hallucinations or agitation), and wishes of patients and families to maintain the patient at home for as long as feasible. As with physical restraints, if pharmacologic management is judged necessary, these medications should only be prescribed following an informed consent discussion detailing the associated risks. Depending on state law, health care agents and conservators may need special court authorization to consent to use of such restraints.

\section{Advanced Stages}

While nearly all surrogate decision-makers for patients with advanced dementia believe that comfort should be the primary goal of care, ${ }^{33}$ many patients undergo burdensome interventions and hospitalizations inconsistent with these goals. For example, tube feeding is associated with medical complications, takes away the pleasure of eating (for which hand feeding is preferred), and has not been shown to improve survival, quality of life, nutrition, or wound healing. ${ }^{34}$ Ethical challenges arise when surrogate decision-makers nonetheless request tube feeding. While respect for autonomy (extended to the surrogate as the patient's representative) does not compel clinicians to provide interventions without medical justification, feeding and nutrition have great symbolic significance for many families. Such requests should be treated as occasions for deeper conversations about the surrogate's perception of the medical benefits of artificial nutrition and their understanding of the patient's overall prognosis.

Patients with advanced dementia may also experience underrecognition and undertreatment of pain due to communication difficulties. Validated pain measures based on caregiver assessment can be useful in these circumstances. ${ }^{35}$

One in 6 patients with advanced dementia die in hospitals, and many others undergo burdensome transitions between hospitals and institutional settings. ${ }^{36}$ In part because of the high morbidity of inpatient delirium and nosocomial infection, most conditions including pneumonia are best managed in outpatient settings. Hospitalization often occurs by "default" in perceived crises due to insufficient advance planning and preparation of patients' family members and can in many cases be prevented by anticipatory discussion and the use of do-not-hospitalize 
orders in nursing homes when transfers are unlikely to extend survival or improve quality of life.

\section{Hospice and the Problem of Prognostication}

Many patients with advanced dementia would benefit from hospice enrollment, which is associated with reduced hospitalization, greater symptom control for pain and dyspnea, and increased family satisfaction with care. ${ }^{37}$ While hospice utilization in dementia is increasing, over $20 \%$ of those dying in hospice with dementia only use hospice for 3 days or fewer prior to death. ${ }^{38} \mathrm{~A}$ major policy barrier to earlier hospice utilization for dementia in the United States is that Medicare eligibility requires an estimated survival of less than 6 months based on the Functional Assessment Staging scale, but these guidelines are little better than chance at predicting mortality in dementia. ${ }^{39}$ The development of better predictive measures and of eligibility requirements more appropriate to advanced dementia would enable patients and families to utilize hospice services earlier in the course of illness.

\section{Addressing Requests for Physician-Hastened Death}

Physician-hastened death (often referred to as physician aidin-dying or physician-assisted suicide) has been legalized in several US states, and neurologists have increasingly fielded inquiries from patients and families regarding this practice. ${ }^{40}$ US state laws legalizing physician-hastened death (modeled after the Oregon Death with Dignity Act) generally do not apply to patients with dementia, as they require (1) an estimated survival of 6 months or less and (2) that the patient requesting a lethal medication have decisional capacity and be capable of self-administration. (Such requests also must be contemporaneous and cannot be made by advance directive.) Still, neurologists have a responsibility to respond empathetically to such inquiries, which can provide opportunities to elicit deeper concerns from patients and their families (including patients' fears of being a "burden") or to address unmet palliative, psychosocial, and advance care planning needs. Treatable causes of physical and psychological suffering should be addressed; mental health, palliative care, or hospice referral should be made if appropriate; and planning documents such as advance health care directives, do-nothospitalize orders, and POLST orders should be reviewed and updated.

\section{Contextual Issues}

\section{Financial Effects}

Some of the fear and stigma associated with dementia may be attributable to the financial strains it can place on patients' families. In dementia, the overwhelming majority of costs are attributable to in-home care, nursing home care, and lost caregiver wages for unpaid care, all of which are generally directed at patient impairments in activities of daily living and thus are not covered by medical insurance but instead are predominantly borne by patients' families. ${ }^{41}$ Most American families are ill-prepared for these expenses; planning is also hampered by a widespread misconception that Medicare will cover patients' long-term care expenses. ${ }^{42}$ Newer models of providing and financing long-term care are needed to address the needs of patients and their families.

\section{The Caregiver Role}

Family members and other unpaid caregivers are crucial clinical partners in dementia care; for patients with memory deficits, their input is often crucial to obtaining an adequate clinical history, and clinical plans usually depend on them for successful implementation. As discussed above, caregiver strain and burnout are key mediators of institutionalization, so realistic plans to care for the patient at home should anticipate and minimize them; caregiver strain and burnout are also risk factors for patient abuse (discussed below). Some research has suggested that emotional and physical burdens associated with caregiving result in negative health outcomes for the caregiver, although more recent population-based studies indicate more positive emotional and physiologic effects of caregiving. ${ }^{43}$ Health effects and positive experiences of caregiving are strongly influenced by social support as well as cultural and relational factors ${ }^{44}$; the financial, emotional, and physical costs of caregiving are disproportionately borne by women. ${ }^{45}$ Many caregivers may be unaware of existing programs to provide respite care, financial support, and other services and can often benefit from targeted referrals from social work. ${ }^{46}$ These programs can be key tools for maintaining patients in home and community (rather than institutional) settings, and more resources are needed to provide economic and social services support to caregivers.

Progressive communication and memory deficits often complicate a patient's ability to provide a clinical history; thus, during many office visits a caregiver will act as the spokesperson. While the caregiver's perspective is critical, patients have their own perspective that should be elicited and acknowledged; there is often a temptation to omit this as timeconsuming. Following core ethical principles of beneficence (concern for the patient's well-being) and respect for patient autonomy (even when diminished), clinicians should be mindful to express both in words and by actions that their primary duty is fidelity to the patient, even when the caregiver is relied upon to speak on the patient's behalf.

\section{Abuse of the Patient With Dementia}

Patients with dementia and other cognitive impairments are at increased risk for abuse, which can take various forms including physical and psychological abuse, sexual assault, financial exploitation, and neglect. ${ }^{47}$ Perpetrators of abuse may include family members, friends, and providers of health care or longterm care services; in nursing homes, there is growing recognition of the problem of resident-to-resident aggression. ${ }^{48}$ Clinicians should be alert to identify and document potential manifestations of abuse, such as supportive examination findings, direct observations of abusive actions, isolation of the patient from previously trusted family or friends, failure to pay for care needs, and malnutrition. ${ }^{49}$ In many cases it is necessary to devise strategies for interviewing the patient separately from 
a suspected abuser. There is a common misconception that reporting to Adult Protective Services requires convincing evidence; instead, in almost all US states, physicians and other mandated reporters are obligated to report any reasonable suspicion of abuse. Typically, reports will result in a home visit by a worker from Adult Protective Services to investigate these concerns, which patients with capacity may refuse. Every state also has mechanisms for reporting the suspicion of abuse in nursing homes and other long-term care facilities. ${ }^{49}$

\section{Socioeconomic, Racial/Ethnic, and Cultural Factors}

Black and Latinx older adults are at increased risk for dementia compared with White and Asian American older adults; this increased risk appears not to reflect genetic differences but instead the influence of social determinants of health such as reduced access to primary care and early life adversity. ${ }^{50} \mathrm{Di}$ agnosis of dementia in Black and Latinx patients is also often delayed due to lack of access to specialist care, differing family and patient expectations around cognitive change and caregiving, and clinicians' reliance upon culturally specific screening and testing materials that do not generalize to the patient's population. ${ }^{51,52}$ Another factor in delayed diagnosis may be mistrust towards the medical establishment among minority communities, informed both by awareness of historical abuses (including but not limited to the Tuskegee Syphilis Study) as well as by patients' personal experiences of biased, discriminatory, or culturally insensitive treatment by clinicians. ${ }^{53}$

When evaluating patients who are not fluent in English, clinicians should strive whenever possible to use professional interpreters rather than rely on family members as translators. Many family members would have difficulty in objectively translating a patient's or another family member's report of the patient's cognitive decline or in communicating challenging information back to the patient about the diagnosis. Clinicians should be aware that patients and families whose ethnic or cultural background differs from their own may have different perceptions of illness and priorities for care than they do, while not assuming that all members of a given group or family have identical communication and treatment preferences. ${ }^{54}$

\section{Multidisciplinary Care and Systems of Care}

Providing high-quality dementia care is often challenging due to the fragmentation of our health care system and incentives that often favor technical and invasive interventions over personal attention. Patients are often cared for by multiple specialists in a variety of hospitals and nursing facilities, often with incompatible electronic records systems. This fragmentation, added to the inherent challenges of care management in dementia, likely contributes to potentially preventable and burdensome acute hospitalizations. ${ }^{55}$ Policy efforts have emphasized the need for more integrated models of care delivery, in order to anticipate and address the varied psychosocial as well as physiologic effects of dementia on patients and families. ${ }^{56,57}$ As one related development, Medicare has introduced Chronic Care Management billing codes to incentivize care coordination activities beyond face-to-face office visits, such as medication reconciliation, communications with specialists, coordination with home- and communitybased service providers, and care planning. However, it remains unclear whether many practices will be able to take advantage of these payments. ${ }^{58}$ Further research and policy innovations are needed to foster a practice environment in which neurologists can best provide care that is respectful of patient autonomy, advances patients' welfare, and minimizes harms, and in which the benefits of care are distributed justly among all patients.

\section{Acknowledgment}

The authors thank Sarah Hooper, Jalayne Arias, Joanne Taylor, Cynthia Barton, and Sharon Kaufman for input on earlier drafts of this manuscript and Cailin Lechner for assistance in compiling and formatting references. Katharina M. Busl, Robin Conwit, Salvador Cruz-Flores, Leon G. Epstein, William Graf, Matthew Kirschen, Julie Kurek, Dan Larriviere, Ariane Lewis, Justin A. Sattin, Ericka P. Simpson, Lynne Taylor, and Laura Vernon participated in the development of this report and guidance as members of the AAN Ethics, Law, and Humanities Committee and Sarah Bird Nelson and Karen Kasmirski facilitated discussion and approval of this report as AAN staff.

\section{Study Funding}

This is not a funded research study but a position statement of the Ethics, Law, and Humanities Committee (a joint committee of the AAN, ANA, and CNS).

\section{Disclosure}

The authors report no discloses. Go to Neurology.org/N for full disclosures.

\section{Publication History}

Received by Neurology May 1, 2020. Accepted in final form March 8, 2021.

Appendix 1 Authors

\begin{tabular}{lll}
\hline Name & Location & Contribution \\
\hline $\begin{array}{l}\text { Winston } \\
\text { Chiong, MD, } \\
\text { PhD }\end{array}$ & $\begin{array}{l}\text { University of California San } \\
\text { Francisco }\end{array}$ & $\begin{array}{l}\text { Design and concept, } \\
\text { drafted manuscript }\end{array}$ \\
\hline $\begin{array}{l}\text { Amy Y. Tsou, } \\
\text { MD }\end{array}$ & $\begin{array}{l}\text { ECRI Evidence-based Practice } \\
\text { Center, Michael J. Crescenz VA }\end{array}$ & $\begin{array}{l}\text { Design and concept, } \\
\text { drafted manuscript }\end{array}$ \\
\hline $\begin{array}{l}\text { Zachary } \\
\text { Simmons, MD }\end{array}$ & $\begin{array}{l}\text { Pennsylvania State University, } \\
\text { Hershey }\end{array}$ & $\begin{array}{l}\text { Design and concept, } \\
\text { drafted manuscript }\end{array}$ \\
\hline $\begin{array}{l}\text { Richard J. } \\
\text { Bonnie, LLB }\end{array}$ & $\begin{array}{l}\text { University of Virginia, } \\
\text { Charlottesville }\end{array}$ & $\begin{array}{l}\text { Revised for } \\
\text { intellectual content }\end{array}$ \\
\hline $\begin{array}{l}\text { James A. } \\
\text { Russell, Do }\end{array}$ & $\begin{array}{l}\text { Lahey Medical Center, Burlington, } \\
\text { MA }\end{array}$ & $\begin{array}{l}\text { Design and concept, } \\
\text { revised for } \\
\text { intellectual content }\end{array}$ \\
\hline
\end{tabular}


Appendix 2 Coinvestigators

\begin{tabular}{|c|c|c|c|}
\hline Name & Location & Role & Contribution \\
\hline $\begin{array}{l}\text { Katharina } \\
\text { M. Busl, } \\
\text { MD, MS }\end{array}$ & University of Florida & $\begin{array}{l}\text { Study } \\
\text { group } \\
\text { member }\end{array}$ & $\begin{array}{l}\text { Participated in statement } \\
\text { development as a } \\
\text { member of the Ethics, } \\
\text { Law, and Humanities } \\
\text { Committee }\end{array}$ \\
\hline $\begin{array}{l}\text { Robin A. } \\
\text { Conwit, } \\
\text { MD }\end{array}$ & $\begin{array}{l}\text { National Institutes of } \\
\text { Health }\end{array}$ & $\begin{array}{l}\text { Study } \\
\text { group } \\
\text { member }\end{array}$ & $\begin{array}{l}\text { Participated in statement } \\
\text { development as a } \\
\text { member of the Ethics, } \\
\text { Law, and Humanities } \\
\text { Committee }\end{array}$ \\
\hline
\end{tabular}

Salvador Paul L. Foster School of Study Participated in statement

Salvador Paul L Foster School of Study Participated in statement

Cruz- Medicine Texas Tech group development as a

Flores, MD University Health member member of the Ethics,

Sciences Center Law, and Humanities

Committee

\begin{tabular}{llll}
\hline Leon G. & Lurie Children's Hospital \\
Epstein, & of Chicago & $\begin{array}{l}\text { Study } \\
\text { group }\end{array}$ & $\begin{array}{l}\text { Participated in statement } \\
\text { development as a }\end{array}$ \\
MD & & member & member of the Ethics, \\
& & Law, and Humanities \\
& & Committee
\end{tabular}

William D. Connecticut Children's Study Participated in statement Graf, MD Medical Center group development as a member member of the Ethics, Law, and Humanities Committee

\begin{tabular}{llll}
\hline $\begin{array}{l}\text { Matthew } \\
\text { Kirschen, } \\
\text { MD, PhD }\end{array}$ & $\begin{array}{l}\text { Children's Hospital of } \\
\text { Pennsylvania }\end{array}$ & $\begin{array}{l}\text { Study } \\
\text { group } \\
\text { member }\end{array}$ & $\begin{array}{l}\text { Participated in statement } \\
\text { development as a } \\
\text { member of the Ethics, } \\
\text { Law, and Humanities } \\
\text { Committee }\end{array}$ \\
\hline $\begin{array}{l}\text { Julie A. } \\
\text { Kurek, MD }\end{array}$ & Augusta University & $\begin{array}{l}\text { Study } \\
\text { group } \\
\text { member }\end{array}$ & $\begin{array}{l}\text { Participated in statement } \\
\text { development as a } \\
\text { member of the Ethics, } \\
\text { Law, and Humanities } \\
\text { Committee }\end{array}$ \\
& & &
\end{tabular}

Daniel G. Inova Neuroscience and Study Participated in statement Larriviere, Spine Institute group development as a MD, JD member member of the Ethics, Law, and Humanities Committee

\begin{tabular}{|c|c|c|c|}
\hline $\begin{array}{l}\text { Ariane } \\
\text { Lewis, MD }\end{array}$ & $\begin{array}{l}\text { NYU Langone Medical } \\
\text { Center }\end{array}$ & $\begin{array}{l}\text { Study } \\
\text { group } \\
\text { member }\end{array}$ & $\begin{array}{l}\text { Participated in statement } \\
\text { development as a } \\
\text { member of the Ethics, } \\
\text { Law, and Humanities } \\
\text { Committee }\end{array}$ \\
\hline
\end{tabular}

\begin{tabular}{llll}
\hline $\begin{array}{l}\text { Justin A. } \\
\text { Sattin, MD }\end{array}$ & University of Wisconsin & $\begin{array}{l}\text { Study } \\
\text { group } \\
\text { member }\end{array}$ & $\begin{array}{l}\text { Participated in statement } \\
\text { development as a } \\
\text { member of the Ethics, } \\
\text { Law, and Humanities } \\
\text { Committee }\end{array}$ \\
\hline $\begin{array}{l}\text { Ericka P. } \\
\text { Simpson, }\end{array}$ & Houston Methodist & $\begin{array}{l}\text { Study } \\
\text { group } \\
\text { member }\end{array}$ & $\begin{array}{l}\text { Participated in statement } \\
\text { development as a }\end{array}$ \\
& & $\begin{array}{l}\text { member of the Ethics, } \\
\text { Law, and Humanities } \\
\text { Committee }\end{array}$
\end{tabular}

\begin{tabular}{llll}
\hline Lynne P. & University of & $\begin{array}{l}\text { Study } \\
\text { group } \\
\text { Taylor, MD }\end{array}$ & $\begin{array}{l}\text { Participated in statement } \\
\text { development as a }\end{array}$ \\
& & & member of the Ethics, \\
& & Law, and Humanities \\
Committee
\end{tabular}

\begin{tabular}{llll}
\hline Laura & Lurie Children's Hospital \\
$\begin{array}{l}\text { Vernon, } \\
\text { of Chicago }\end{array}$ & $\begin{array}{l}\text { Study } \\
\text { group } \\
\text { member }\end{array}$ & $\begin{array}{l}\text { Participated in statement } \\
\text { development as a }\end{array}$ \\
& & $\begin{array}{l}\text { member of the Ethics, } \\
\text { Law, and Humanities } \\
\text { Committee }\end{array}$ \\
& &
\end{tabular}

\section{References}

1. American Academy of Neurology. Ethics and Humanities Subcommittee: ethical issues in the management of the demented patient. Neurology. 1996;46(4):1180-1183.

2. Herrmann LK, Welter E, Leverenz J, et al. A systematic review of dementia-related stigma research: can we move the stigma dial? Am J Geriatr Psychiatry. 2018;26(3): 316-331.

3. Tolchin B, Conwit R, Epstein LG, Russell JA; Ethics, Law, and Humanities Committee, a joint committee of the American Academy of Neurology, American Neurological Association, and Child Neurology Society. AAN position statement: ethical issues in clinical research in neurology. Neurology. 2020;94(15):661-669.

4. Trachtenberg DI, Trojanowski JQ. Dementia: a word to be forgotten. Arch Neurol. 2008;65(5):593-595.

5. Ganguli M, Blacker D, Blazer DG, et al. Classification of neurocognitive disorders in DSM-5. Am J Geriatr Psychiatry. 2011;19(3):205-210.

6. Bostick NA, Sade R, McMahon JW, Benjamin R. Report of the American Medical Association Council on Ethical and Judicial Affairs: withholding information from patients: rethinking the propriety of "therapeutic privilege." J Clin Ethics. 2006;17(4):302.

7. Aoun SM, Breen LJ, Howting D, et al. Receiving the news of a diagnosis of motor neuron disease: what does it take to make it better? Amyotroph Lateral Scler Frontotemporal Degener. 2016;17(3-4):168-178.

8. Dubois B, Hampel H, Feldman HH, et al. Preclinical Alzheimer's disease: definition, natural history, and diagnostic criteria. Alzheimers Dement. 2016;12(3):292-323.

9. Goldman JS, Hahn SE, Catania JW, et al. Genetic counseling and testing for Alzheimer disease: joint practice guidelines of the American College of Medical Genetics and the National Society of Genetic Counselors. Genet Med. 2011;13(6):597-605.

10. Quaid KA. Genetic testing for Huntington disease. Handb Clin Neurol. 2017;144: 113-126.

11. Johnson KA, Minoshima S, Bohnen NI, et al. Appropriate use criteria for amyloid PET: a report of the Amyloid Imaging Task Force, the Society of Nuclear Medicine and Molecular Imaging, and the Alzheimer's Association. Alzheimers Dement. 2013; 9(1):e1-e16.

12. Fink HA, Linskens EJ, Silverman PC, et al. Accuracy of biomarker testing for neuropathologically defined Alzheimer disease in older adults with dementia. Ann Intern Med. 2020;172(10):669-677.

13. Mozersky J, Sankar P, Harkins K, Hachey S, Karlawish J. Comprehension of an elevated amyloid positron emission tomography biomarker result by cognitively normal older adults. JAMA Neurol. 2018;75(1):44-50.

14. Rothstein MA. GINA at ten and the future of genetic nondiscrimination law. Hastings Cent Rep. 2018;48(:5-7.

15. Arias JJ, Tyler AM, Oster BJ, Karlawish J. The proactive patient: long-term care insurance discrimination risks of Alzheimer's disease biomarkers. J Law Med Ethics. 2018;46(2):485-498

16. Su XW, Simmons Z. Ethical considerations in neurogenetic testing. Semin Neurol. 2018;38(5):505-514.

17. ACMG Board of Directors. Direct-to-consumer genetic testing: a revised position statement of the American College of Medical Genetics and Genomics. Genet Med. 2016;18(2):207.

18. Appelbaum PS. Assessment of patients' competence to consent to treatment. N Engl J Med. 2007;357(18):1834-1840.

19. Kim SY. Evaluation of Capacity to Consent to Treatment and Research. Oxford University Press;. 2010.

20. Shalowitz DI, Garrett-Mayer E, Wendler D. The accuracy of surrogate decision makers: a systematic review. Arch Intern Med.. 2006;166(5):493-497.

21. Institute of Medicine. Committee on Approaching Death. Addressing Key End-Of-Life Issues. Dying in America: Improving Quality and Honoring Individual Preferences Near the End of Life. National Academies Press;. 2015.

22. Amundson R. Quality of life, disability, and hedonic psychology. J Theor Soc Behav. 2010;40(4):374-392.

23. Moore KA, Rubin EB, Halpern SD. The problems with physician orders for lifesustaining treatment. JAMA. 2016;315(3):259-260.

24. Sabatino CP. Damage prevention and control for financial incapacity. JAMA. 2011; 305(7):707-708.

25. Livingston G, Sommerlad A, Orgeta V, et al. Dementia prevention, intervention, and care. Lancet.. 2017;390(10113):2673-2734.

26. Iverson DJ, Gronseth GS, Reger MA, Classen S, Dubinsky RM, Rizzo M. Practice parameter update: evaluation and management of driving risk in dementia: report of the Quality Standards Subcommittee of the American Academy of Neurology. Neurology. 2010;74(16):1316-1324.

27. Ryu SH, Katona C, Rive B, Livingston G. Persistence of and changes in neuropsychiatric symptoms in Alzheimer disease over 6 months: the LASER-AD study. Am J Geriatr Psychiatry. 2005;13(11):976-983.

28. Yaffe K, Fox P, Newcomer R, et al. Patient and caregiver characteristics and nursing home placement in patients with dementia. JAMA. 2002;287(16):2090-2097.

29. Kales HC, Gitlin LN, Lyketsos CG. Assessment and management of behavioral and psychological symptoms of dementia. BMJ.. 2015;350(7):h369.

30. Centers for Medicare \& Medicaid Services. Freedom from Unnecessary Physical Restraints: Two Decades of National Progress in Nursing Home Care. Department of Health and Human Services;. 2008:9. Report No.: S\&C-09-11. Available at: cms.gov/ Medicare/Provider-Enrollment-and-Certification/SurveyCertificationGenInfo/ downloads/SCLetter09-11.pdf. Accessed August 24, 2020.

31. Konetzka RT, Brauner DJ, Shega J, Werner RM. The effects of public reporting on physical restraints and antipsychotic use in nursing home residents with severe cognitive impairment. J Am Geriatr Soc. 2014;62(3):454-461. 
32. Yunusa I, Alsumali A, Garba AE, Regestein QR, Eguale T. Assessment of reported comparative effectiveness and safety of atypical antipsychotics in the treatment of behavioral and psychological symptoms of dementia: a network meta-analysis. JAMA Netw Open. 2019;2(3):e190828.

33. Mitchell SL, Teno JM, Kiely DK, et al. The clinical course of advanced dementia. N Engl J Med. 2009;361(16):1529.

34. Mitchell SL. Advanced dementia. N Engl J Med. 2015;372(26):2533-2540.

35. Warden V, Hurley AC, Volicer L. Development and psychometric evaluation of the Pain Assessment in Advanced Dementia (PAINAD) scale. J Am Med Dir Assoc. 2003, 4(1):9-15.

36. Teno JM, Gozalo PL, Bynum JP, et al. Change in end-of-life care for Medicare beneficiaries: site of death, place of care, and health care transitions in 2000, 2005, and 2009. JAMA. 2013;309(5):470-477.

37. Miller SC, Lima JC, Looze J, Mitchell SL. Dying in U.S. nursing homes with advanced dementia: how does health care use differ for residents with, versus without, end-oflife Medicare skilled nursing facility care? J Palliat Med. 2012;15(1):43-50.

38. Teno JM, Gozalo PL, Bynum JP, et al. Change in end-of-life care for Medicare beneficiaries: site of death, place of care, and health care transitions in 2000, 2005, and 2009. JAMA. 2013;309(5):470-477.

39. Mitchell SL, Miller SC, Teno JM, Kiely DK, Davis RB, Shaffer ML. Prediction of 6-month survival of nursing home residents with advanced dementia using ADEPT vs hospice eligibility guidelines. JAMA. 2010;304(17):1929-1935.

40. Russell JA, Epstein LG, Bonnie RJ, et al. Lawful physician-hastened death AAN position statement. Neurology. 2018;90(9):420-422.

41. Hurd MD, Martorell P, Delavande A, Mullen KJ, Langa KM. Monetary costs of dementia in the United States. N Engl J Med. 2013;368(14):1326-1334.

42. Benz J, Tompson TN, Willcoxon N, et al. Long-Term Care in America: Expectations and Reality. Associated Press-NORC Center for Public Affairs Research. 2014:1-17. Available at: longtermcarepoll.org/report-long-term-care-in-america-expectationsand-reality/. Accessed August 24, 2020.

43. Roth DL, Fredman L, Haley WE. Informal caregiving and its impact on health: a reappraisal from population-based studies. Gerontologist. 2015;55(2):309-319.

44. Roth DL, Dilworth-Anderson P, Huang J, Gross AL, Gitlin LN. Positive aspects of family caregiving for dementia: differential item functioning by race. J Gerontol Psychol Sci Soc Sci. 2015;70(6):813-819.

45. Bott NT, Sheckter CC, Milstein AS. Dementia care, women's health, and gender equity: the value of well-timed caregiver support. JAMA Neurol. 2017;74:757-758.
46. American Association of Retired Persons. AARP. Can I get paid to be a caregiver for family member?. 2020. Available at: aarp.org/caregiving/financial-legal/info-2017/ you-can-get-paid-as-a-family-caregiver.html. Accessed August 24, 2020.

47. Pillemer K, Burnes D, Riffin C, Lachs MS. Elder abuse: global situation, risk factors, and prevention strategies. Gerontologist. 2016;56(S2):S194-S205.

48. Lachs MS, Teresi JA, Ramirez M, et al. The prevalence of resident-to-resident elder mistreatment in nursing homes. Ann Intern Med. 2016;165(4):229-236.

49. Lachs MS, Pillemer KA. Elder abuse. N Engl J Med. 2015;373(20):1947-1956.

50. Alzheimer's Association. 2018 Alzheimer's disease facts and figures. Alzheimers Dement. 2018;14(3):367-429.

51. Manly JJ, Mayeux R. Ethnic differences in dementia and Alzheimer's disease. In: Anderson NB, Bulatao RA, Cohen B, eds. National Research Council (US) Panel on Race, Ethnicity, and Health in Later Life. National Academies Press; 2004.

52. Dilworth-Anderson P, Pierre G, Hilliard TS. Social justice, health disparities, and culture in the care of the elderly. J Law Med Ethics. 2012;40(1):26-32.

53. Chin AL, Negash S, Hamilton R. Diversity and disparity in dementia: the impact of ethnoracial differences in Alzheimer disease. Alzheimer Dis Assoc Disord. 2011;25: 187-195.

54. Kleinman A, Benson P. Anthropology in the clinic: the problem of cultural competency and how to fix it. PLoS Med. 2006;3(10):e294.

55. Phelan EA, Borson S, Grothaus L, et al. Association of incident dementia with hospitalizations. JAMA. 2012;307:165-172.

56. Sico JJ, Sarwal A, Benish SM, et al. Quality improvement in neurology: neurology outcomes quality measurement set. Neurology. 2020;94(22):982-990.

57. Quality Payment Program. US Department of Health and Human Services. Explore Measures.. 2018. Available at: qpp.cms.gov/mips/explore-measures/quality-measures?py=2018\&search=dementia. Accessed August 24, 2020.

58. Basu S, Phillips RS, Bitton A, Song Z, Landon BE. Medicare chronic care management payments and financial returns to primary care practices: a modeling study. Ann Intern Med. 2015;163(8):580-588.

59. Brodoff L. Planning for Alzheimer's disease with mental health advance directives. Elder Law J. 2009;17(2):239-308.

60. American Bar Association Commission on Law and Aging. Default surrogate consent statutes.. 2019. Available at: americanbar.org/content/dam/aba/administrative/law_aging/2019-sept-default-surrogate-consent-statutes.pdf. Accessed August 24, 2020

\section{Get NeuroReady!}

Preparing for the neurology boards? Up for recertification? Looking for a solid foundational knowledge in neurology? Get ready with the AAN's convenient online courses-NeuroReady: Board Prep Edition or NeuroReady: Continuing Certification Edition, and the new NeuroReady: Advanced Practice Provider Edition. Includes 12 months of access. Get ready to review, self-assess, and succeed at AAN.com/NeuroReady.

\section{Announcing... Child Neurology: A Case-Based Approach Cases From the Neurology Resident \& Fellow Section}

This collaboration between the American Academy of Neurology (AAN) and the Child Neurology Society (CNS) represents a collection of reprinted cases from the past 15 years from the Neurology Resident \& Fellow Section.

An invaluable resource for both adult and pediatric neurologists and trainees! FREE download: NPub.org/cnbook 


\section{Neurology}

\section{Ethical Considerations in Dementia Diagnosis and Care: AAN Position Statement}

Winston Chiong, Amy Y. Tsou, Zachary Simmons, et al.

Neurology 2021;97;80-89

DOI 10.1212/WNL.0000000000012079

This information is current as of July 12, 2021

\section{Updated Information \& Services}

References

Citations

Subspecialty Collections

\section{Permissions \& Licensing}

Reprints including high resolution figures, can be found at: http://n.neurology.org/content/97/2/80.full

This article cites 52 articles, 5 of which you can access for free at: http://n.neurology.org/content/97/2/80.full\#ref-list-1

This article has been cited by 2 HighWire-hosted articles: http://n.neurology.org/content/97/2/80.full\#\#otherarticles

This article, along with others on similar topics, appears in the following collection(s):

All Cognitive Disorders/Dementia

http://n.neurology.org/cgi/collection/all_cognitive_disorders_dementia All Ethics in Neurology/Legal issues

http://n.neurology.org/cgi/collection/all_ethics_in_neurology_legal_iss ues

All Neuropsychology/Behavior

http://n.neurology.org/cgi/collection/all_neuropsychology_behavior Models of care

http://n.neurology.org/cgi/collection/models_of_care

Information about reproducing this article in parts (figures,tables) or in its entirety can be found online at:

http://www.neurology.org/about/about_the_journal\#permissions

Information about ordering reprints can be found online:

http://n.neurology.org/subscribers/advertise

Neurology ${ }^{\circledR}$ is the official journal of the American Academy of Neurology. Published continuously since 1951, it is now a weekly with 48 issues per year. Copyright @ 2021 American Academy of Neurology. All rights reserved. Print ISSN: 0028-3878. Online ISSN: 1526-632X.

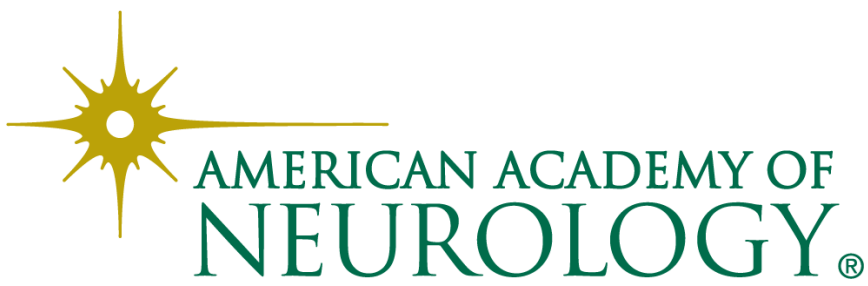

